\title{
Safe Practices for Copy and Paste in the EHR
}

\section{Systematic Review, Recommendations, and Novel Model for Health IT Collaboration}

Amy Y. Tsou ${ }^{1,2}$; Christoph U. Lehmann ${ }^{3}$; Jeremy Michel1,4,5; Ronni Solomon; Lorraine Possanza'; Tejal Gandhi ${ }^{6,7}$

${ }^{1}$ ECRI Institute, Plymouth Meeting, PA;

${ }^{2}$ Division of Neurology, Michael J Crescenz Veterans Affairs Medical Center, Philadelphia, PA;

${ }^{3}$ Departments of Biomedical Informatics \& Pediatrics, Vanderbilt University Medical Center, Nashville, TN;

${ }^{4}$ Department of Biomedical and Health Informatics, The Children's Hospital of Philadelphia, Philadelphia, PA;

${ }^{5}$ Department of Pediatrics, Perelman School of Medicine, University of Pennsylvania, Philadelphia, PA;

${ }^{6}$ National Patient Safety Foundation, Boston, MA, USA;

${ }^{7}$ Department of Medicine, Harvard Medical School, Boston, MA, USA

\section{Keywords}

Copy and paste, electronic health records, information technology, health policy, patient safety, clinical documentation

\section{Summary}

Background: Copy and paste functionality can support efficiency during clinical documentation, but may promote inaccurate documentation with risks for patient safety. The Partnership for Health IT Patient Safety was formed to gather data, conduct analysis, educate, and disseminate safe practices for safer care using health information technology (IT).

Objective: To characterize copy and paste events in clinical care, identify safety risks, describe existing evidence, and develop implementable practice recommendations for safe reuse of information via copy and paste.

Methods: The Partnership 1) reviewed 12 reported safety events, 2) solicited expert input, and 3) performed a systematic literature review (2010 to January 2015) to identify publications addressing frequency, perceptions/attitudes, patient safety risks, existing guidance, and potential interventions and mitigation practices.

Results: The literature review identified 51 publications that were included. Overall, $66 \%$ to $90 \%$ of clinicians routinely use copy and paste. One study of diagnostic errors found that copy and paste led to $2.6 \%$ of errors in which a missed diagnosis required patients to seek additional unplanned care. Copy and paste can promote note bloat, internal inconsistencies, error propagation, and documentation in the wrong patient chart. Existing guidance identified specific responsibilities for authors, organizations, and electronic health record (EHR) developers. Analysis of 12 reported copy and paste safety events was congruent with problems identified from the literature review.

Conclusion: Despite regular copy and paste use, evidence regarding direct risk to patient safety remains sparse, with significant study limitations. Drawing on existing evidence, the Partnership developed four safe practice recommendations: 1) Provide a mechanism to make copy and paste material easily identifiable; 2 ) Ensure the provenance of copy and paste material is readily available; 3 ) Ensure adequate staff training and education; 4) Ensure copy and paste practices are regularly monitored, measured, and assessed. 


\section{Correspondence to:}

Amy Y. Tsou, MD, MSc

Health Technology Assessment Group

AHRQ ECRI-Penn Evidence Based Practice Center (EPC)

ECRI Institute

5200 Butler Pike

Plymouth Meeting, PA 19462-1298

atsou@ecri.org

+1 (610) 825-6000 ext 5705

\section{Appl Clin Inform 2017; 8: 12-34}

https://doi.org/10.4338/ACl-2016-09-R-0150

received: September 8, 2016

accepted: November 7, 2016

published: January 11, 2017

Citation: Tsou AY, Lehmann CU, Michel J, Solomon R, Possanza L, Gandhi T: Safe practices for copy and paste in the EHR: Systematic review, recommendations, and novel model for Health IT collaboration. Appl Clin Inform 2017; 8: 12-34

https://doi.org/10.4338/ACI-2016-09-R-0150

Funding

The Partnership for Health IT Patient Safety was funded in part through a grant from the Jayne Koskinas Ted Giovanis Foundation (JKTG) for Health and Policy. 


\section{Introduction}

Many clinicians use the copy and paste functionality provided by operating systems in electronic health records (EHRs) to improve usability by allowing providers to insert text with test results or exam information, maintain stable medication lists, and improve documentation efficiency, particularly when systems lack interoperability. However, copy and paste may also promote longer, poorly organized, and less accurate notes due to inclusion of redundant, outdated, or inconsistent information [1]. In a large physician survey, 25\% agreed that copy and paste makes progress notes more likely to lead to a mistake in patient care [1]. Subsequently, professional organizations including the American Health Information Management Association, the Association of Medical Directors of Information Systems, and the Federation of State Medical Boards have formally addressed aspects of copy and paste use in position/guidance statements [2,3]. Additionally, copy and paste may enable reimbursement fraud, allowing users to easily attest to care they have not provided. Nevertheless, a recent report by the U.S. Office of the Inspector General found that only $24 \%$ of organizations had a copy and paste policy in place [4].

The Partnership for Health IT Patient Safety (The Partnership) was formed to gather data, conduct analysis, provide education, and disseminate recommended practices with the goal of enabling safer care using health information technology (IT). The Partnership collectively decided to establish single-topic workgroups addressing particular patient safety issues; the first workgroup was established to address the practice of copy and paste. This workgroup was composed of a diverse group of stakeholders including vendors, providers, representatives from professional organizations, academicians, and safety experts. Although cognizant of the regulatory, legal, and compliance issues around reimbursement fraud, the workgroup intentionally focused on identifying clinical risks and possible interventions for safe copy and paste functionality to improve patient safety.

\section{Objective}

The workgroup was tasked with assessing the nature and scope of patient safety risks associated with copy and paste, identifying potential solutions, developing practice recommendations and implementation strategies to facilitate safe reuse of information via copy and paste. To inform the recommendation development process, submitted copy and paste events were analyzed. To ensure development of recommendations informed by up-to-date evidence, we also performed a systematic review of the literature addressing the following key questions:

1. What is the prevalence of copy and paste in the EHR?

2. How can copy and paste lead to adverse events?

3. What are the associations between copy and paste and adverse patient events?

4. What best practices or recommendations exist to address proper use of copy and paste?

\section{Methods}

\subsection{Overview of The Partnership for Health IT Patient Safety workgroup process}

The Partnership's multi-stakeholder workgroup convened in February 2015 and met monthly for six months. During this time the workgroup reviewed copy and paste events, discussed results from the systematic literature review, and solicited presentations from topic experts across different stakeholder groups. Based on these deliberations and drawing on the eight-part sociotechnical model [5], the workgroup developed recommendations and implementation strategies for the safe use of copy and paste.

The Partnership also collected data under the protection of a patient safety organization (ECRI Institute PSO). Data from adverse events and hazards were submitted by providers and provider organizations using the Agency for Healthcare Research and Quality (AHRQ) Common Formats and HIT Hazard Manager taxonomies. Events reported from 2013 to 2015 were de-identified and de- 
scribed for analysis. Two experienced patient safety analysts from ECRI Institute Patient Safety Organization (PSO) performed this analysis. Although the ECRI Institute PSO also collects data from alerts, root-cause analyses, and help desk logs, no copy and paste events were reported through those sources.

\subsection{Characterization of copy and paste functionality}

For this work, the workgroup used the following definition of copy and paste: Selecting data from an original or previous source to reproduce in another location; obtaining this data volitionally from another part of the record and reusing it without retyping any information. This action may be performed by keyboard command or mouse. Other terms for copy and paste include copy functionality, cut and paste, cloning, whole note cloning, carry or copy forward, autofill, and autocomplete. These terms reflect differences in how information is obtained, reused or brought forward in a record. The workgroup did not address safe use of cut and paste functionality due to concerns about inadvertent removal of data from the EHR.

\subsection{Literature Review}

To identify existing evidence, we searched PubMed, MEDLINE, EMBASE, CINAHL, Journals@OVID, ScienceDirect, Scopus, PS Net, and the Agency for Healthcare Research and Quality Web Morbidity and Mortality for published studies and conference abstracts from January 2010 through January 2015 using a search strategy developed by a medical librarian (search strategy available in supplemental online material $>$ Appendix A). Bibliographies of identified studies were reviewed and relevant additional articles prior to the search dates were included. Gray literature was retrieved by searching the publications and websites of relevant vendors, professional organizations, private agencies, and government agencies. Study review and data extraction was performed by a single physician analyst. Studies primarily addressing use of copy and paste associated with reimbursement fraud were excluded. Otherwise, all studies which addressed a key question were included.

\subsection{Workgroup deliberation and recommendation development}

To ensure input from key stakeholders, the workgroup reviewed vendor alternatives to copy and paste, examples of practices that promoted safer use of copy and paste, and presentations from several professional organizations and subject matter experts. Workgroup members were then asked to prioritize a list of all potential identified solutions. Using the highest-ranked potential solutions, the workgroup drafted preliminary recommendations, which were ranked according to feasibility, importance, and impact. Recommendations were also categorized based on means of implementation (e.g., through regulation, technology, education, or policy and procedures) and effect on each stakeholder group (providers, provider organizations, vendors, professional organizations, and patients). To promote feasibility and completeness, each recommendation was assessed using Sittig and Singh's sociotechnical model [5].

\section{Results}

\subsection{Systematic Literature Review}

To inform the workgroup's deliberation, a comprehensive literature search was performed which identified 233 potentially relevant studies, articles, and reports. Of these, we included 51 articles addressing prevalence, patient safety outcomes, and guidance for copy and paste use. Detailed descriptions of all included articles can be found in supplementary online Appendices B and C. Below we summarize key findings from the literature. 


\subsubsection{Prevalence}

Thirteen studies and two conference abstracts described the prevalence of copy and paste ( Table 1). In published studies, 66 to $90 \%$ of medical students, residents, and attending physicians reported using copy and paste for documentation, with one large physician survey reporting that $78 \%$ used copy and paste "almost always" or "most of the time" for inpatient documentation. Notably, one survey of 143 dermatology residents, found that $83 \%$ reported copying a prior author's past medical history, social history, or family history without confirming the information's accuracy.[6] Study definitions of copy and paste varied widely, and in some cases, were not provided $(>$ Table 2).

Retrospective chart reviews identified highly variable rates of copy and paste use, depending on clinical context. For instance, Edwards et al. reviewed a random sample of 239 outpatient primary care, cardiology, and endocrinology notes and found that $10.8 \%$ contained copied material (although a definition of copy and paste was not provided) [7]. Conversely, another study of ICU notes (A/P section) found that $82 \%$ of resident and $74 \%$ of attending notes contained copied elements (defined as $\geq 20 \%$ copied text from another document) [8].

Thielke et al. (2006) [9] evaluated how often mental status, podiatry and general physical exams appeared to be copied. After excluding text from discharge summaries, $25 \%$ of charts contained $\geq 1$ copied exam and $11 \%$ contained $>1$ exam copied from another author. Notably, most copying (more than $80 \%$ ) was performed by only a small fraction of authors (4.2\%). Another small review of 60 randomly selected charts from admitted patients found that nearly $20 \%$ of all inpatient notes (372 of 1,891 ) contained copied material, and physicians were responsible for a substantial proportion of copied notes (50\%) [10]. Most copying (nearly 90\%) was found to include substantial edits; only $1.6 \%$ (6 of 372) of notes were copied forward without changes, and only 1 note $(0.3 \%)$ was copied from another provider without modification.

\subsubsection{Adverse Events}

\subsubsection{Clinical Harms}

Our search identified two studies reporting a relationship between copy and paste use and clinical outcomes. An analysis of Veteran's Health Administration (VA) medical records by Singh et al. (2013) found that copy and paste contributed to clinical diagnostic errors [11]. The study identified all cases in which a patient's primary care visit was followed by unplanned further medical care within 14 days (e.g. return primary care, urgent care, emergency room visit, or unplanned hospital admission). Physician reviewers then considered each case to determine if a diagnostic error (e.g. adequate information suggesting the correct diagnosis was already available at initial visit) was responsible. Within 212,165 visits over a 1-year span at 2 large urban medical centers they detected 190 diagnostic errors (when adequate information or information which should have prompted a workup was available to make the correct diagnosis). In $7.4 \%$ of these errors, a practitioner had copied and pasted prior notes into the progress note; of these cases, copy and pasting mistakes contributed to $35.7 \%$ of errors (2.6\% of total errors identified). No details regarding the nature of these copy and paste mistakes or resultant adverse patient outcomes were provided.

A second study by Turchin et al. found that copied lifestyle counseling statements were associated with less effective glucose control for diabetic patients. Compared to copied and pasted statements of lifestyle counseling, noncopied or "distinct" statements were associated with a significant improvement in HgbA1c among patients with diabetes: an increase of 1 monthly counseling episode was associated with a hazard ratio of $4.35(\mathrm{p}<0.001)$ for reaching HgbAlc target. In contrast, copied/duplicate counseling or absent statements had no effect on glucose control [12].

We also identified several case reports of clinical harm related to copy and paste. In one case, a chemotherapy patient with a history of pulmonary embolus was admitted for diarrhea and dehydration. The admission note specified that the patient should receive heparin for venous thromboembolism prophylaxis, but heparin was never ordered. On transfer to another service, this statement was copied and pasted for five days, with authors presumably assuming standard venous thromboembolism prophylaxis with heparin was administered, although the accuracy of information in the admission note was never verified, and heparin was neither ordered nor administered. 
Shortly after discharge, the patient developed a pulmonary embolus and required readmission [13-15].

In another case, a patient was discharged from the emergency room after a new diagnosis of atrial fibrillation and potential heart disease; he was instructed to follow up with his primary care physician (PCP) for a stress test [16]. However, the PCP failed to diagnose cardiac disease and copied and pasted the A/P over 12 office visits during the next 2 years. The patient died from a heart attack and the physician was found liable in the death [16]. In another case, an infant was seen for fever, rash, and fussiness. The initial EHR note documented no history of tuberculosis (TB) exposure, despite the infant's recent travel to a TB endemic country. Successive office visits propagated this erroneous negative exposure to TB using copy and paste for two weeks until the child was diagnosed with TB meningitis in the emergency room and left with significant residual deficits [17].

\subsubsection{Other Harms}

We also identified reports of chart inaccuracies propagated by copy and paste resulting in non-clinical harm $[13,14,18,19]$. For instance, one physician began a conversation with the family of a comatose patient by mistakenly stating that the patient had recently undergone surgery, when in fact, the patient's description as postoperative day 2 had been copied daily in the progress notes for 5 and half weeks [20]. This mistake created mistrust between the family and physician which could not be repaired. Other cases resulted in problems with insurance coverage and delayed discharge $[21,22]$.

\subsubsection{How does copy and paste lead to adverse patient events?}

Review of existing guidance, reviews, and opinion pieces indicated four major ways in which copy and paste could compromise the quality of clinical information and impair good clinical care ( Table 3), namely:

1. Facilitating introduction of new inaccuracies,

2. Accelerating propagation of inaccurate information,

3. Promoting creation of internally inconsistent notes, and

4. Generating lengthy notes that may obscure important clinical information ("note bloat").

\subsubsection{Responsibilities for authors, organizations, and EHR developers}

Existing guidance from a wide variety of professional organizations (summarized in supplementary online Appendix C) suggested specific responsibilities for authors, organizations, and suggestions for EHR developers. Authors are responsible for verifying the accuracy of all copied content regardless of the source $[23,24]$, and the original source of copied text should always be acknowledged, particularly if copying from another provider $[18,23,25]$. Also, authors should strive for brevity and avoid propagating irrelevant/redundant text that might obscure new or important information [23, 26]. Finally, in particular contexts, copy and pasting should never be allowed (e.g., a physician copying a medical student's exam [27]).

Organizations were urged to provide clarity for documentation standards (e.g., what information is permissible to copy) and specify consequences for violations [2, 25, 28]. Additionally, healthcare organizations were urged to provide ongoing education and feedback to medical personnel after these standards are established $[2,18,23,29]$.

Several suggestions for EHR modifications to potentially address these problems were identified ( Table 4). There was widespread consensus that EHRs should develop functionalities to allow easy identification of copied material, potentially through altering font color, highlighting copied text, or linking between different documents $[18,30,31]$. Other suggestions attempted to address "note bloat" due to copy and pasting [2, 3]. Several suggestions were aimed at improving display of data, including using toggles to decrease information overload [3], separating sections requiring frequent updates from more stable sections [32], and a "Wiki" design in which multiple authors could contribute [26]. Finally, several authors suggested standard incorporation of audit or tracking capability into EHR design to allow ongoing monitoring of copy and paste, and timely feedback to users regarding proper and improper use [18, 33]. 


\subsubsection{Benefits of copy and paste}

Many articles acknowledged important benefits of copy and paste when properly used [23, 30, 34]. Nearly $80 \%$ of physicians agreed that copy and paste has improved documentation of the entire hospital course, and $82 \%$ agreed that copy and paste use should continue [1]. In fact, forcing providers to retype information may lead to more errors [34]. Although copy and paste may promote note bloat, it may also promote more timely documentation. At one institution, residents kept extraneous test results within the patient's daily note to facilitate easy conversion into a discharge summary [35]. One study found that compared to dictated surgical discharge summaries, electronic summaries were completed significantly faster and were shorter in length [36]. Other potential benefits of copy and paste include higher continuity in medical decision-making, more complete documentation of clinical encounters, and systematized tracking of patient problem lists [23].

\subsection{Exploration of Patient Safety Data}

In addition to the literature review, the workgroup also considered 12 cases of events and hazards submitted to ECRI Institute Patient Safety Organization (PSO) between 2013 and 2015 ( Table 5). These events were organized first by the system involved as well as standardized tagging taxonomies (AHRQ, HM, Magrabi) [37-39]. Overall, these events were consistent with copy and paste use and associated problems described in the literature. No sentinel or serious events were reported; instead, events described instances in which copy and paste created potential hazards that could cause a diagnostic error if undetected. In one case, two separate pathology specimens received the same label because information was copied and pasted. Other events reported copying of lab and X-ray results into the wrong patient charts, and in another, pharmacy directions were copied to facilitate label printing, but were discovered to be inaccurate.

Taken together, cases illustrated that copy and paste errors

1. occur across a wide variety of clinical settings,

2. have the potential to cause patient harm and delay diagnosis, and

3. have associated risks that can be mitigated with improved detection.

Providers are only recently recognizing and reporting the contributing role of copy and paste in hazards and events.

\subsection{Additional insights from key stakeholder experts}

Input from key stakeholder experts generally concurred with the concerns expressed in the literature. There was widespread agreement about the importance of copy and paste for promoting EHR usability and documentation efficiency. However, experts agreed that information should never be copied in certain contexts, including signature lines, copying between different charts, and any information that has not been read and edited. Particular concerns not specifically addressed in detail in the literature are violations of HIPAA (Health Insurance Portability and Accountability Act), False Claims Act (due to inappropriate billing), and privacy issues. This was best demonstrated through a submitted safety event evaluated by the workgroup, where one patient noticed that another patient's information had been copy and pasted into the medical record and brought this to the attention of a health care provider ( Table 5).

\subsection{Workgroup Deliberation}

Utilizing input from the literature review, submitted events and hazards, input from various vendors, current organization practices, and topic experts, the Partnership workgroup identified key areas of focus for safe practice recommendations. Each of the potential recommendations was evaluated and prioritized using the sociotechnical model with a focus on patient safety. 


\subsection{Safe Practice Recommendations}

Drawing on analysis of reported event data, results from the systematic literature review and input from a variety of stakeholders, the Partnership's workgroup arrived at the following conclusions and developed four safe practice recommendations for copy and paste which were released in February 2016 ( Table 6). Rationale and recommendations are presented below.

These recommendations are intended to support a provider's ability to easily assess whether information reused outside of its original context was correct, timely, and relevant. As these recommendations primarily focused on patient safety, organizations are encouraged to continue to evaluate the impact of implementation of specific approaches to the recommended safe practices on HIPAA compliance, billing practices, and regulatory implications.

Rationale for Recommendation A: To protect and enhance patient safety, clinical documentation (regardless of process of creation) must be accurate, reliable, and timely. Reusing information in the electronic environment through copy and paste to document complex medical conditions can ensure completeness of encounter documentation and generally produces fewer transcription errors. However, information that is inaccurate, out of date, or from an inappropriate source (e.g., copied into the wrong chart) can compromise clinical decision-making. To ensure accuracy, reliability, and appropriateness, copied and pasted information must be verified before final submission. To achieve this goal, copied and pasted information should be readily visible and recognizable as copied material so that it can be reviewed, confirmed, and validated.

\section{Recommendation A}

Provide a mechanism to make copy and paste material easily identifiable.

Rationale for Recommendation B: Authors — in addition to being able to easily recognize when text has been copied to verify the accuracy of charted material - may also need to know the source, context, author, time, and date of the source information. Without this information, authors may have difficulty verifying the accuracy, applicability, reliability, and timeliness of documentation.

\section{Recommendation B}

Ensure that the provenance of copy and paste material is readily available.

Rationale for Recommendation C: Improper use of copy and paste information can jeopardize patient safety and may cause inaccurate, inappropriate, or outdated information to be used in clinical decision making. Outlining proper procedures for copying and pasting information can standardize the process to ensure staff is following appropriate and best practice guidelines, facilitate regulatory compliance, and ensure that the record will be useful in the event of litigation.

\section{Recommendation C}

Ensure adequate staff training and education regarding the appropriate and safe use of copy and paste.

Rationale for Recommendation D: Audit trails identify key activities necessary to detect improper or unsafe use of copy and paste. Implementation of an audit policy will allow organizations and providers to monitor how copy and paste is used to identify safety issues and offer physicians and staff alternative ways to reuse correct and current information, when applicable, to make patient care safer. Monitoring will help ensure that the identified solutions are appropriate and effective.

\section{Recommendation D}

Ensure that copy and paste practices are regularly monitored, measured and assessed.

\subsection{Implementation Tools and Resources}

Recognizing the challenge of translating recommendations into individual contexts, the Partnership also developed a publically available toolkit (https://www.ecri.org/resource-center/Pages/HIT-Safe- 
Practices.aspx ) with resources for clinical leadership, professional organizations as well as the vendor and developers. The toolkit contains implementation aids for organizations including a training checklist, educational presentations, risk identification assessments (tailored for various stakeholders), and self-assessment checklists. Also included are templates for policies and procedures and implementation plans and strategies for each of the stakeholder groups, along with audit and assessment tools which can be used to assess successful implementation.

\section{Discussion}

As demonstrated by the literature and reported safety events, evidence around the important health IT patient safety issue of copy and paste remains limited both in quantity and quality. Several studies failed to even provide basic definitions of copy and paste. Adverse patient events due to copy and paste are multifactorial and involve several missed opportunities for detection. Nevertheless, the literature clearly suggests a majority of physicians use copy and paste regularly with potential deleterious effects on the accuracy and usability of data within the EHR and with risks to patient safety. We identified one study demonstrating a causative link between copy and paste and errors resulting in the need for urgent unplanned care (Singh et al. demonstrated that copy and paste errors contributed to $2.6 \%$ of overall errors). Furthermore, reported events, while few, confirm that copy and paste occur in multiple areas of clinical care, and that although alternatives to copy and paste (such as vendor supplied functionalities) are available, they remain infrequently used and inadequate to address all the ways information is reused.

\subsection{Recommendation implementation and potential impact}

A detailed description of the work group's recommendations, their anticipated impact, and how they fit into the sociotechnical model is provided in $>$ Table 6 and $>$ Figure 1 . The sociotechnical model provided a vehicle to evaluate key factors impacting the recommendations [5]. This model also provided a framework to ensure all aspects of the healthcare process were taken into account during development of implementation strategies. Additionally, the sociotechnical model can facilitate monitoring and assessment of potential changes in care resulting from implementation of the safe practice recommendations. With consideration of the sociotechnical model in mind, we highlight key aspects and implementation considerations below.

Recommendation A suggests providing a mechanism to make copy and paste material easily identifiable. This implementation will require new software functionality. Since such features are currently not widely available, implementation may prove expensive and may slow systems with the potential result of being disabled by users. Anecdotally, several organizations reported to the workgroup that they experienced significant system slowing after introducing this feature. Altering the display of copied material may also pose additional readability challenges: the use of varying fonts, colors, or hover notifications may clutter the note, particularly if documents contain blocks of information from a variety of sources. Despite these obstacles, vendors have made progress towards allowing easy identification of documentation source - a key first step to allow readers the ability to assess the source, veracity, and relevance of information in the EHR.

Recommendation B states that the provenance (or original source) of copied material should be readily available. Given time constraints, authors cannot re-confirm all information in the chart and necessarily rely on prior information within the record. However, to determine if information is upto-date and accurate, providers could benefit from knowing when the information was obtained and by whom. Such information could be displayed in a variety of ways including hover notification, a split screen, hypertext, or separate log files, which authors could access, but would not necessarily be displayed by default. In addition to clinical utility, tracking this information could allow for better monitoring of clinical compliance and more nuanced claims in cases of medical liability. Again, potential obstacles to providing such functionality are largely technical and vendor involvement in the workgroup during the development of these recommendations provides an indication of the implementability of these recommendations. 
The workgroup's third recommendation regarding staff training and education should reflect organizational awareness of copy and paste associated issues, and should also be reflected in local policies and culture. Staff training should improve awareness of good documentation practices, knowledge of material that is appropriate to copy, and alternative functions for inserting material into the note (e.g. auto-populating text via macros). Educational initiatives should also encourage users to avoid using workarounds to bypass policy and technological limits placed on copy and paste functionality. While education plays a prominent role in implementing these safe practices for copy and paste, it is just the beginning. Those participating in the Partnership felt that they could readily implement this recommendation and adopt associated policies and processes given that only a limited number of organizations have these in place.

Finally, the workgroup's fourth recommendation pertains to the ability to monitor and assess copy and paste practices. As with prior recommendations, such capabilities are not yet widely available and are likely to require software and potentially hardware modifications. However, the creation of audit capacity and policies on how feedback to users should be provided represent a crucial part of addressing the problems associated with copy and paste. Without monitoring and feedback, assessing the impact of staff training and occurrence of unsafe documentation practices would not be feasible. In addition to promoting better documentation, audit trails may also help to ensure that authors are compliant with various regulatory requirements. Pointing organizations to their own documentation practices and highlighting the potential for patient safety risks associated with improper copying and pasting may encourage those organizations to implement these recommendations. Finally, monitoring copy and paste practices may allow identification of workflows with high copy and paste use, for which a technical solution could decrease reliance.

\subsection{The Partnership for Health IT Patient Safety workgroup as a novel model}

We believe the formation of The Partnership for Health IT Patient Safety and subsequent efforts of the Partnership copy and paste workgroup represent a unique and valuable model for meeting the important and complex challenges facing health IT. First, the complexity and scale of health IT patient safety risks, such as those derived from copy and paste involve multiple key stakeholders, ranging from individual EHR users, patient safety experts, researchers, healthcare organizations and obviously EHR vendors. As a collaborative group comprised of key stakeholders with varied expertise, the copy and paste workgroup was uniquely positioned to understand, analyze, vet potential solutions, and craft implementable recommendations to address unsafe copy and paste use and promote patient safety.

Another unique aspect of the Partnership copy and paste workgroup's process was a decision to perform a systematic literature search to inform the recommendation development process. The 2011 Institute of Medicine report (now National Academy of Medicine) stipulated the importance of performing a systematic review as the foundation for clinical guideline development [40]. Although the Partnership copy and paste workgroup's output is not intended as a clinical guideline, efforts to make the process evidence-based represent a unique strength of the Partnership's process. Finally, in the future, the Partnership may serve as a forum from which to design and pilot test potential health informatics interventions. We believe the Partnership's process represents a novel collaborative model for addressing not only safe use of copy and paste, but other patient health IT safety issues that will arise with widespread EHR adoption, and ultimately inform the national strategy for HIT patient safety.

The Partnership's safe practice recommendations are designed to serve as a foundation for safe reuse of information moving forward, and are intended to enable stakeholders to identify ways to address copy and paste associated issues and risk. 


\section{Conclusion}

The reuse of information is important for efficient, accurate, and complete clinical documentation. Although copy and paste has facilitated the reuse of information, the copy and paste function also presents inherent safety risks for documentation including propagation of inaccurate information, "note bloat" and has been demonstrated to contribute towards adverse events such as diagnostic errors and need for unplanned urgent care. Current evidence regarding copy and paste remains limited and requires further study both to understand the relationship between copy and paste and adverse events and to investigate the benefits of copy and paste. We believe incorporating the Partnership's safe practice recommendations into daily workflow is an important step towards mitigating safety risks and promoting the safe and effective reuse of information.

\section{Clinical Relevance Statement}

The information identified from the literature review provides insight into the frequency of copy and paste use in the U.S. healthcare system. The Partnership copy and paste workgroup's four safe practice recommendations outline strategies that may assist various healthcare stakeholders (e.g., providers, providing organizations, vendors) in ensuring that copy and paste is used carefully in order to protect patient safety and realize benefits of copy and paste. The associated toolkit provides instructional materials to help stakeholders implement the safe practice recommendations.

\section{Conflict of Interest}

The authors declare that they have no conflicts of interest in the research.

\section{Human Subjects Protections}

No human or animal subjects were included in this project.

\section{Acknowledgements}

The Partnership for Health IT Patient Safety was convened by ECRI Institute and is funded in part through a grant from the Jayne Koskinas Ted Giovanis Foundation (JKTG) for Health and Policy. We also thank the Partnership members and particularly members of the Copy and Paste workgroup for providing valuable input and feedback throughout this process. 


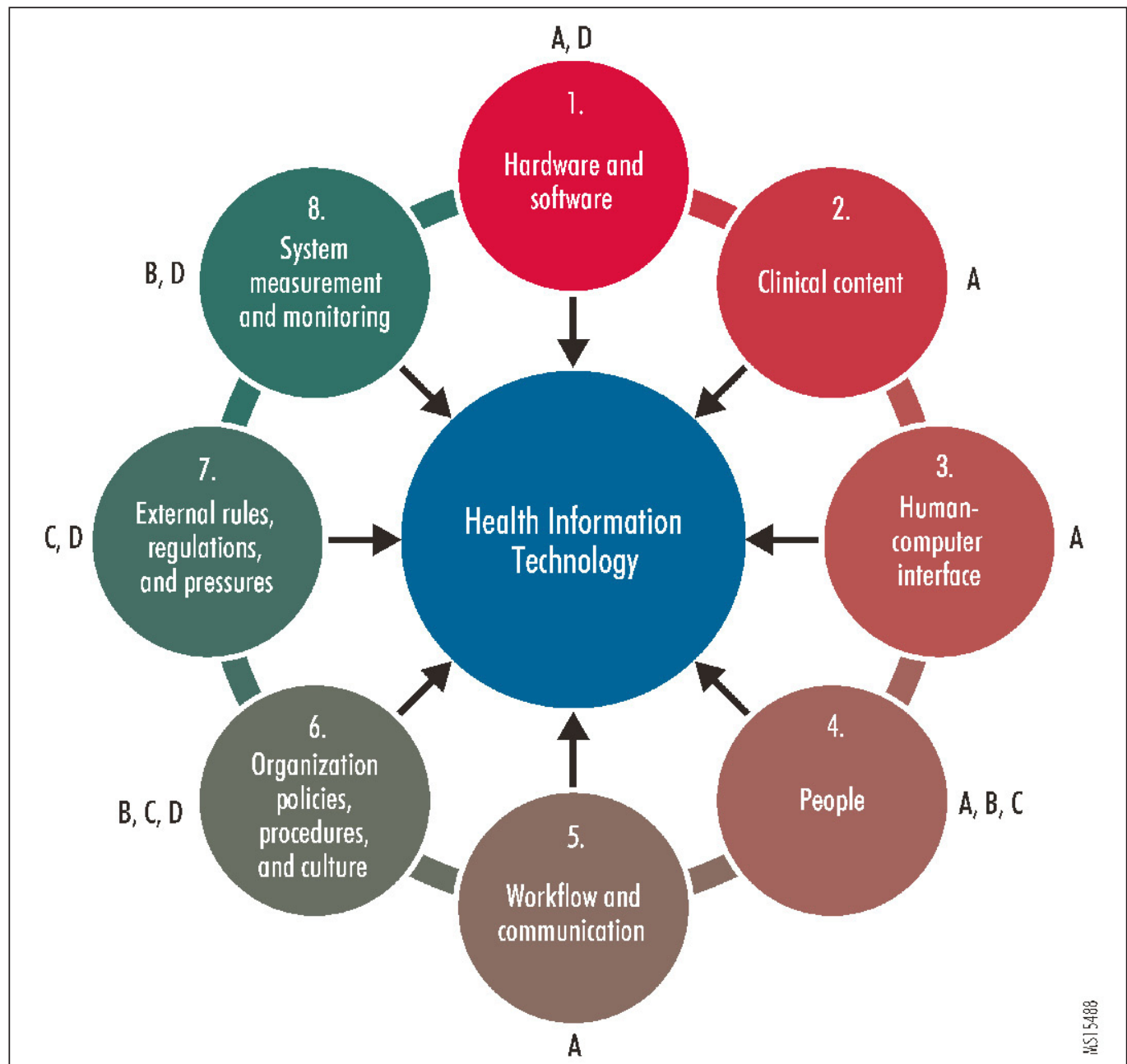

Fig. 1 Copy and Paste Best Practice Recommendations and Associated Sociotechnical Model Components. The different components of the model are keyed to recommendations $A, B, C$, and $D$. 
Table 1 Prevalence of Copy and Paste

\begin{tabular}{|c|c|}
\hline Reference & Prevalence, Context \\
\hline \multicolumn{2}{|c|}{ Self-reported Use of Copy and paste } \\
\hline O'Donnell et al. (2008) [1] & $\begin{array}{l}90 \% \text { of physicians (residents and attendings) using electronic notes reported } \\
\text { the use of copy and paste to write daily inpatient progress notes. } 78 \% \text { used } \\
\text { copy and paste almost always or most of the time. } 81 \% \text { of copy and paste users } \\
\text { frequently copied notes from other physicians or prior admissions. }\end{array}$ \\
\hline Heiman et al. (2014) [41] & $\begin{array}{l}66 \% \text { of Northwestern medical students reported copying their own notes fre- } \\
\text { quently or nearly always. }\end{array}$ \\
\hline Swary et al. (2014) [6] & $\begin{array}{l}83 \% \text { of dermatology residents reported using copy and paste to insert a prior } \\
\text { author's past medical history, family, or social history. }\end{array}$ \\
\hline Tilstra et al. (2014) [42]* & $\begin{array}{l}13 \% \text { of residents and } 7 \% \text { of University of Pittsburgh Medical Center faculty co- } \\
\text { pied from their own prior notes to document outpatient clinic visits at a large } \\
\text { academic center. }\end{array}$ \\
\hline \multicolumn{2}{|l|}{ Chart-based Studies } \\
\hline Edwards et al. (2014) [7] & $\begin{array}{l}10.8 \% \text { of outpatient primary care, cardiology, and endocrinology notes con- } \\
\text { tained copied and pasted material. }\end{array}$ \\
\hline Turchin et al. (2011) [12] & $\begin{array}{l}5 \% \text { of diet counseling, } 5.1 \% \text { of exercise counseling, and } 5.2 \% \text { of weight-loss } \\
\text { counseling documentation by primary care physicians for adult patients with } \\
\text { diabetes was copied. }\end{array}$ \\
\hline Zhang et al. (2013) [31] & $\begin{array}{l}12.3 \% \text { of primary care notes documenting lifestyle counseling were considered } \\
\text { copied from prior notes (by the same author). }\end{array}$ \\
\hline Thornton et al. (2013) [8] & $\begin{array}{l}82 \% \text { of residents' and } 74 \% \text { of attendings' notes in the intensive care unit con- } \\
\text { tained copied text ( } \geq 20 \% \text { copied text from another document). }\end{array}$ \\
\hline Chang et al. (2012) [43]* & $77 \%$ (229 of 299 ) inpatient medicine progress notes contained copied material. \\
\hline Hammond et al. (2003) [44] & $\begin{array}{l}9 \% \text { of all notes (VA Health System) contained copied text, and } 63 \% \text { of these } \\
\text { "copy events" were due to human copying. }\end{array}$ \\
\hline Thielke et al. (2006) [9] & $\begin{array}{l}25 \% \text { of patient charts in a Veterans Affairs (VA) health system contained at } \\
\text { least } 1 \text { copied exam, with the majority of copying performed by a relatively } \\
\text { small fraction of authors. For } 11 \% \text { of patients, charts contained an exam copied } \\
\text { from another author. }\end{array}$ \\
\hline Weir et al. (2003) [10] & $\begin{array}{l}\text { Nearly } 20 \% \text { of inpatient notes for } 60 \text { randomly selected patients (at a VA hospi- } \\
\text { tal) were found to contain copied material and } 43 \text { out of } 60 \text { patient charts con- } \\
\text { tained at least } 1 \text { copied note. }\end{array}$ \\
\hline Reinke et al. (2012) [36] & $\begin{array}{l}8 \% \text { of electronic surgical discharge summaries were found contain copied and } \\
\text { pasted material. }\end{array}$ \\
\hline Shah et al. (2013) [45] & $\begin{array}{l}7 \% \text { of all radiology referrals over } 3 \text { days at a tertiary care children's hospital } \\
\text { contained copied ("cloned") clinical histories. }\end{array}$ \\
\hline \multicolumn{2}{|l|}{ Observational Studies } \\
\hline Mamykina et al. (2012) [46] & $\begin{array}{l}\text { On average, residents were observed to use copy and paste } 0.8 \text { times per note } \\
\text { when writing inpatient progress notes. }\end{array}$ \\
\hline
\end{tabular}

*Only published as conference abstracts 
Table 2 Study definitions of copy and paste

\begin{tabular}{|l|l|}
\hline Reference & Definition \\
\hline O'Donnell et al. (2008) [1] & $\begin{array}{l}\text { Copy-forward functionality was considered copying. However, automatic insertion } \\
\text { of vital signs and results was not classified as copying. }\end{array}$ \\
\hline Turchin et al. (2011) [12] & $\begin{array}{l}\text { A duplicated or copied documentation of lifestyle counseling was defined as } \\
\text { "using a sentence identical to the sentence used to document the same type of } \\
\text { counseling in the previous note by the same health care provider." * }\end{array}$ \\
\hline Zhang et al. (2013) [31] & $\begin{array}{l}\text { Two notes from the same author containing identical sentences to describe life- } \\
\text { style counseling. }\end{array}$ \\
\hline Thornton et al. (2013) [8] & $\begin{array}{l}\text { Copying was defined as: matching phrases }>4 \text { words and } 20 \text { total characters.A } \\
\text { progress note was considered to contain copying if it contained } \geq 20 \% \text { copied } \\
\text { text from another document. }\end{array}$ \\
\hline Thielke et al. (2006) [9] & $\begin{array}{l}\text { A copy-event was defined as } \geq 40 \text { identical consecutive words between } 2 \text { docu- } \\
\text { ments. }\end{array}$ \\
\hline Hammond et al. (2003) [44] & $\begin{array}{l}\text { Phrasing, content, or form }>50 \% \text { identical; assessors then categorized degree of } \\
\text { copying subjectively. }\end{array}$ \\
\hline Weir et al. (2003) [10]
\end{tabular}

*We recognize this definition of copying could also represent other EHR functionalities aside from copy and pasting; however, this definition was used by these studies

Table 3 Copy and paste associated problems that may impair good clinical documentation

\begin{tabular}{|c|c|}
\hline Problem & Description \\
\hline $\begin{array}{l}\text { Creation of new inac- } \\
\text { curacies }\end{array}$ & $\begin{array}{l}\text { Copy and paste can be used to transfer any data. If the source data or the source of the } \\
\text { data is incorrectly copied this could result in a new error within a patient's chart. One } \\
\text { mechanism that may lead to a new inaccuracy could be copying a snippet of a sen- } \\
\text { tence. The snippet, out of context could have a different meaning than the original text. } \\
\text { Copying between sections of the chart can also lead to new inaccuracies. This has been } \\
\text { reported with a family history of cancer erroneously copied as cancer into a patient's } \\
\text { active problem list, ultimately resulting in medical insurers to accuse a patient of with- } \\
\text { holding information [21]. This is also relevant for clinicians working with multiple } \\
\text { charts simultaneously. Frequent copy and pasting (particularly between notes for differ- } \\
\text { ent patients) could increase the risk of depositing text into the wrong chart, resulting in } \\
\text { inaccuracies. }\end{array}$ \\
\hline $\begin{array}{l}\text { Rapid Propagation of } \\
\text { Errors }\end{array}$ & $\begin{array}{l}\text { Copy and paste also enables rapid propagation of errors, once they exist in the medical } \\
\text { record. In one case, an emergency room physician discovered a patient was listed as } \\
\text { having a history of "PE" or pulmonary embolism, although the patient denied this. } \\
\text { After reviewing the chart, the physician found "PE" had originally been used for } \\
\text { "physical exam," but was mistakenly listed under medical history and propagated } \\
\text { throughout the chart for years [18]. }\end{array}$ \\
\hline Internal inconsistencies & $\begin{array}{l}\text { Failure to curate text may lead to internally inconsistencies in the note }[23,30,47] \text {. } \\
\text { Copy and pasting review of systems (ROS) or history of present illness may result in } \\
\text { contradictory statements in which ROS is documented as normal, although the history } \\
\text { of present illness explicitly details it is not [48]. Additionally, a fever might be noted in } \\
\text { a patient's updated vitals, while a copied physical exam states "afebrile, vital signs } \\
\text { stable". Such inconsistencies create dilemmas for clinical personnel who must decide } \\
\text { whether to trust the recorded physical exam [48]. }\end{array}$ \\
\hline Note bloat & $\begin{array}{l}\text { Inclusion of redundant, clinically irrelevant, or outdated information over successive en- } \\
\text { counters can result in a note so long that new or clinically important information is } \\
\text { challenging to identify }[1,23,25,49] \text {. This "note bloat" may lead to lengthy charts } \\
\text { which compromise clinical efficiency. }\end{array}$ \\
\hline
\end{tabular}


Table 4 Continued

\begin{tabular}{|c|c|c|}
\hline $\begin{array}{l}\text { Features of EHR } \\
\text { (References) }\end{array}$ & Benefits & Implementation Considerations \\
\hline $\begin{array}{l}\text { To increase efficiency of workflow } \\
\text { and decrease copy/pasting of re- } \\
\text { dundant information - sections } \\
\text { likely to remain stable over time } \\
\text { (i.e., past medical history) should } \\
\text { be displayed separately from sec- } \\
\text { tions that should require frequent } \\
\text { update (i.e., History of Present III- } \\
\text { ness) (Senathirajah et al. [32]) }\end{array}$ & $\begin{array}{l}\text { - Decreased information overload } \\
\text { - Avoidance of "note bloat" } \\
\text { - Supports a shared patient record }\end{array}$ & $\begin{array}{l}\text { - Separating relatively stable sections } \\
\text { (e.g., past medical history) could } \\
\text { allow users to overlook its clinical } \\
\text { importance. } \\
\text { - Information in separated sections } \\
\text { could change. However, if no version } \\
\text { was inserted into the note at orig- } \\
\text { inal documentation, subsequent } \\
\text { readers could misinterpret reasons } \\
\text { behind care from original authors. } \\
\text { For example, if a patient received a } \\
\text { new diagnosis, a subsequent reader } \\
\text { could find it challenging to deter- } \\
\text { mine which diagnosis a clinician was } \\
\text { working with when a note was } \\
\text { written. } \\
\text { - If patients requested copies of their } \\
\text { note, it could be difficult to present } \\
\text { an accurate representation for older } \\
\text { notes. } \\
\text { - Additional clicks could be required } \\
\text { to access/edit separated informa- } \\
\text { tion. This functionality does not exist } \\
\text { within many EHR systems; imple- } \\
\text { mentation would require creation of } \\
\text { de novo functionality for many sys- } \\
\text { tems. }\end{array}$ \\
\hline $\begin{array}{l}\text { To promote succinct presentation } \\
\text { of information and decrease copy/ } \\
\text { pasting between provider notes, } \\
\text { the chart should be redesigned to } \\
\text { allow for editing by multiple au- } \\
\text { thors (Berkowitz [26]) }\end{array}$ & $\begin{array}{l}\text { - Supports a shared patient record } \\
\text { - Potential to eliminate redundan- } \\
\text { cy: would not require multiple } \\
\text { authors to repeatedly edit past } \\
\text { medical history changes; } 1 \text { auth- } \\
\text { or could make the change, and } \\
\text { future authors could simply con- } \\
\text { firm } \\
\text { - Potential for increased accuracy; } \\
\text { topic "experts" assume responsi- } \\
\text { bility for documenting topic spe- } \\
\text { cific sections (neurologists de- } \\
\text { scribe location and cause of } \\
\text { stroke; surgeons describe particu- } \\
\text { lar procedure) }\end{array}$ & $\begin{array}{l}\text { - Authors may inadvertently remove } \\
\text { important material entered by other } \\
\text { authors; could create medico-legal } \\
\text { concerns. } \\
\text { - Authors may overwrite each other to } \\
\text { describe the truth from their point of } \\
\text { view, which could create medico- } \\
\text { legal concerns. } \\
\text { - Would require accounting for simul- } \\
\text { taneous data entry or for users } \\
\text { being "locked out" of portions of } \\
\text { the note; could create inefficiencies. } \\
\text { This functionality does not exist } \\
\text { within many EHR systems; imple- } \\
\text { mentation would require creation of } \\
\text { de novo functionality for many sys- } \\
\text { tems. }\end{array}$ \\
\hline $\begin{array}{l}\text { To allow tracking of copy and } \\
\text { paste use over time and identify } \\
\text { "high utilizers," EHR should in- } \\
\text { clude functionality to allow regular } \\
\text { audits (Koppel [33]) }\end{array}$ & $\begin{array}{l}\text { Supports organization oversight of } \\
\text { copy and paste and copy-forward } \\
\text { activities }\end{array}$ & $\begin{array}{l}\text { - Certain specialties may be more } \\
\text { likely to appear as "high utilizers" } \\
\text { due to patient stability. }\end{array}$ \\
\hline
\end{tabular}


Table 4 Selected potential EHR modifications from the literature and implementation considerations

\section{Features of EHR (References) \\ To allow easy identification, dis- play of copied material should be altered (i.e., different font, differ- ent color text) (Zhang et al. [31]; ED Legal Letter et al. [18])}

\section{Benefits}

- Easy identification of copied text

- May facilitate author attrition

- Potential deterrent to copying text
To promote acknowledging outside - Avoid "note bloat" information by reference instead of - Decrease the need to copy by reentering information in the body of a note, EHRs should create links between the referenced text and the referring note (American Health Information Management Association et al. [2], Shoolin et al. [3]. Association of Medical Directors of information Systems)

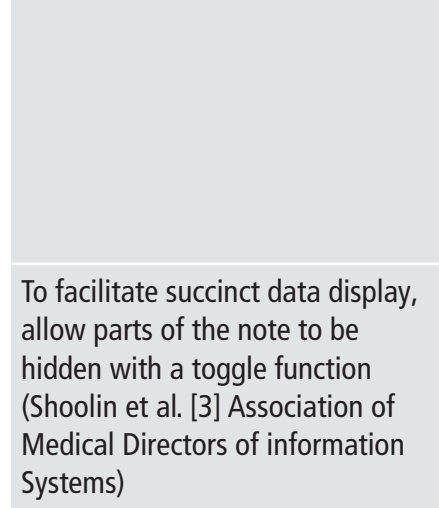
providing an alternative method for maintaining timeliness of information

- Automatic attribution of authorship

- Allows users quick access to original report/note without searching through other records or accessing through separate menu

- May allow users to review original information and form impressions for themselves
- Decreased information overload

- Allows users to "customize" display of information for their own clinical context

- Intuitive data display already widely used; likely easy for users to learn

- Each note would still contain a "complete" record of data (even if hidden).
Implementation Considerations

- Altered text (i.e., multiple fonts, conflicting colors) could be more challenging to read

- Recopied text may become challenging to differentiate

- Compatibility issues (not all systems use the same fonts)

- If users are required to manually alter text, documentation efficiency would decrease

- Information at the link target could change with potential clinical and medical legal implications (e.g., if test results are amended)

- Degradation of links over time could affect the permanence of the document artifact; future users reviewing a record with broken links could lack access to complete record.

- Inserting links instead of complete information could make it more challenging to quickly provide patients with copies of their note.

- As this functionality does not exist within many EHR systems, implementation would require creation of de novo functionality

- If clinically important information is hidden by default, critical information for patient care could be missed - Additional clicks could be required to access certain information

- Would require consensus regarding what should be hidden on a system level, although, preferences could be tailored for groups of users (i.e., surgeons, nurses, pediatricians).

- As this functionality does not exist within many EHR systems; implementation would require creation of de novo functionality for many systems 


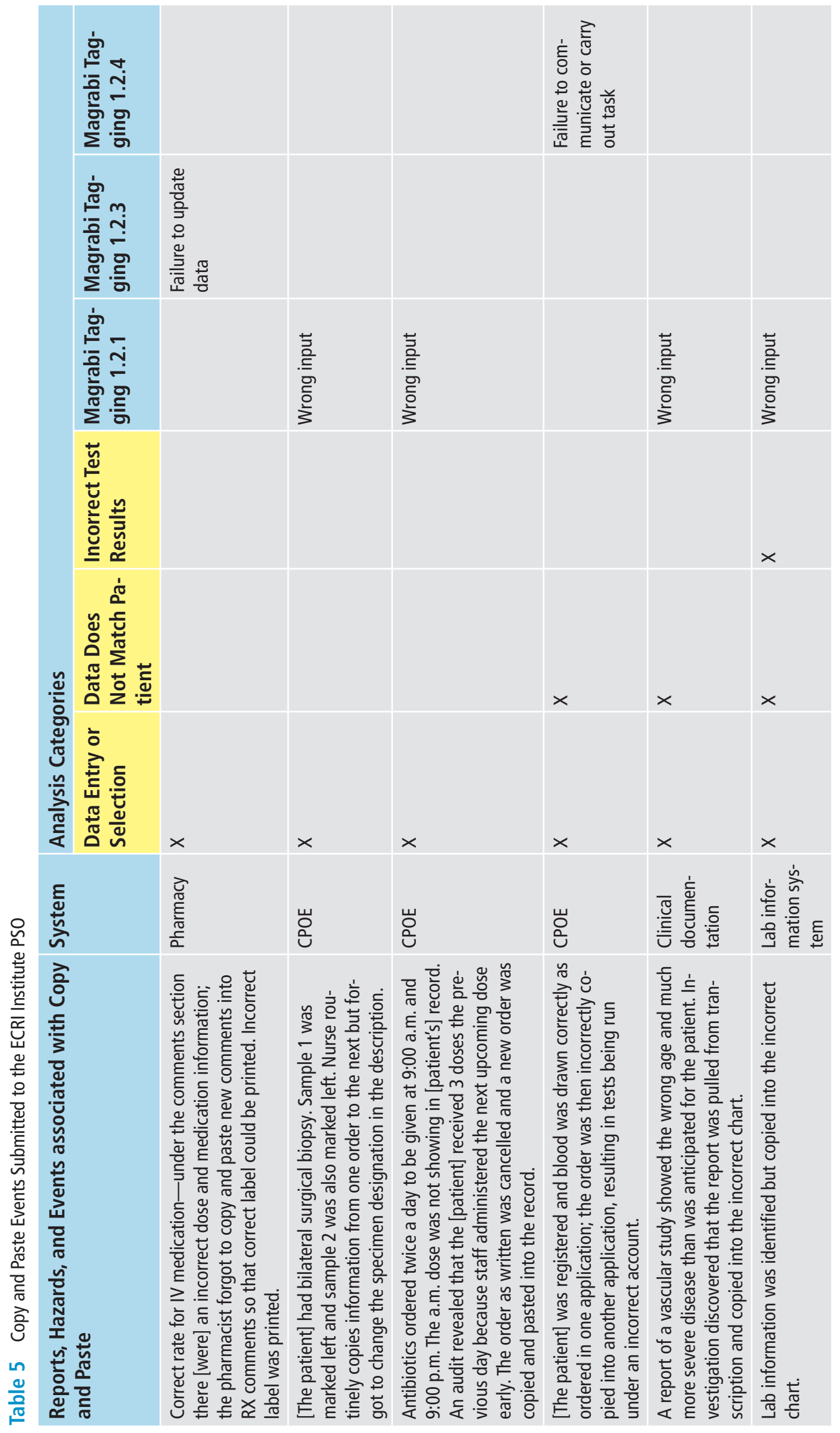




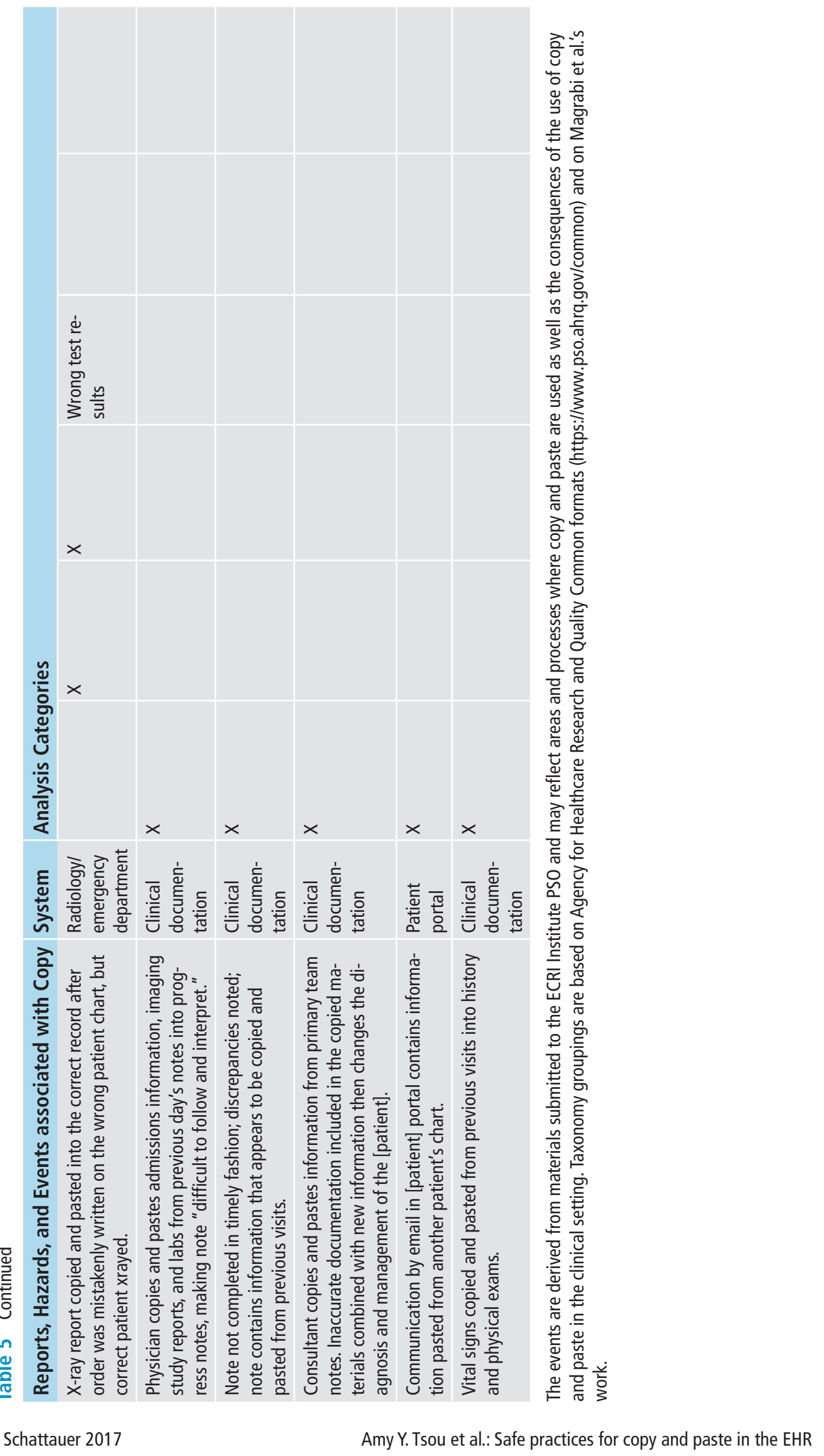




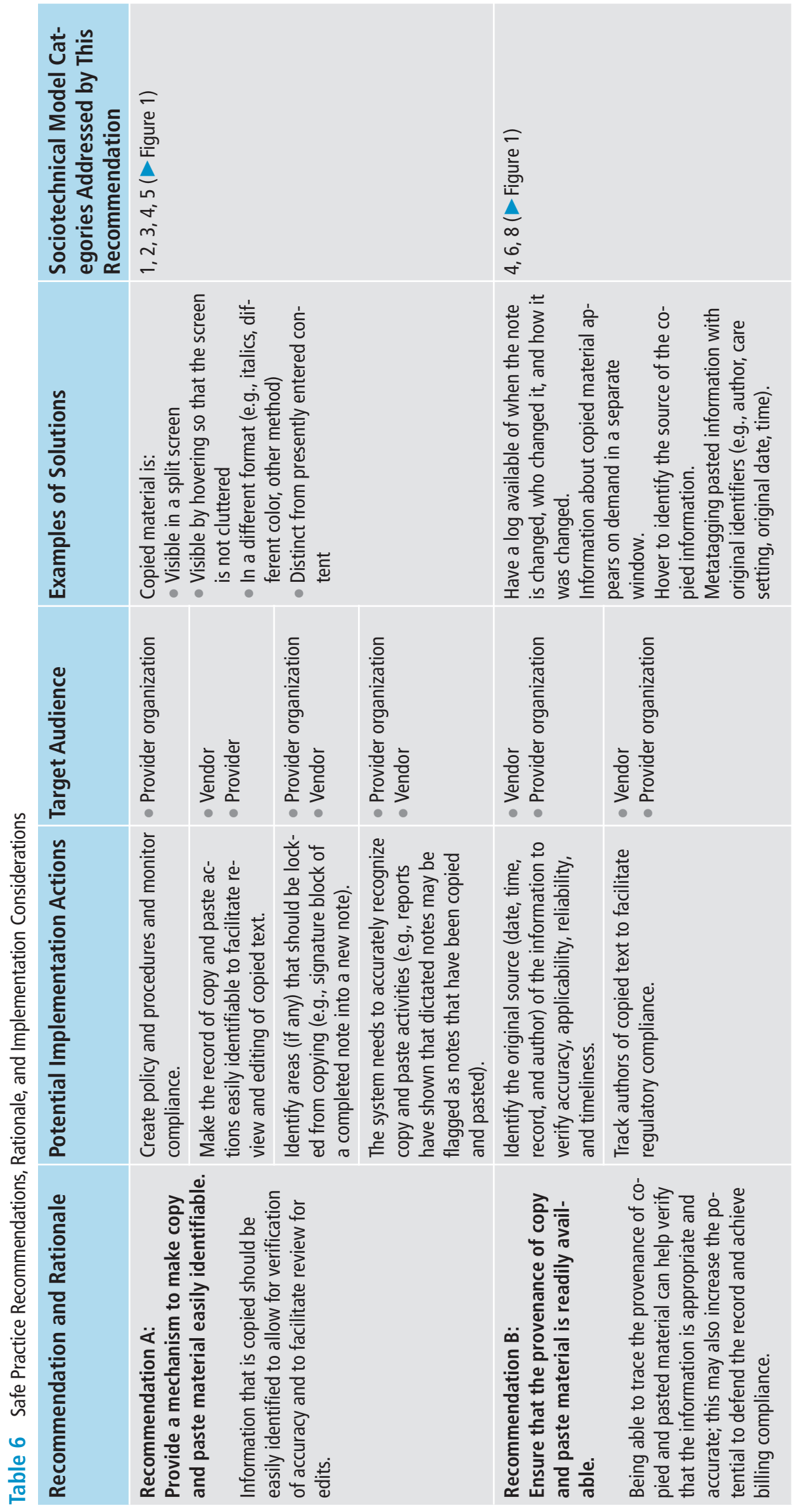



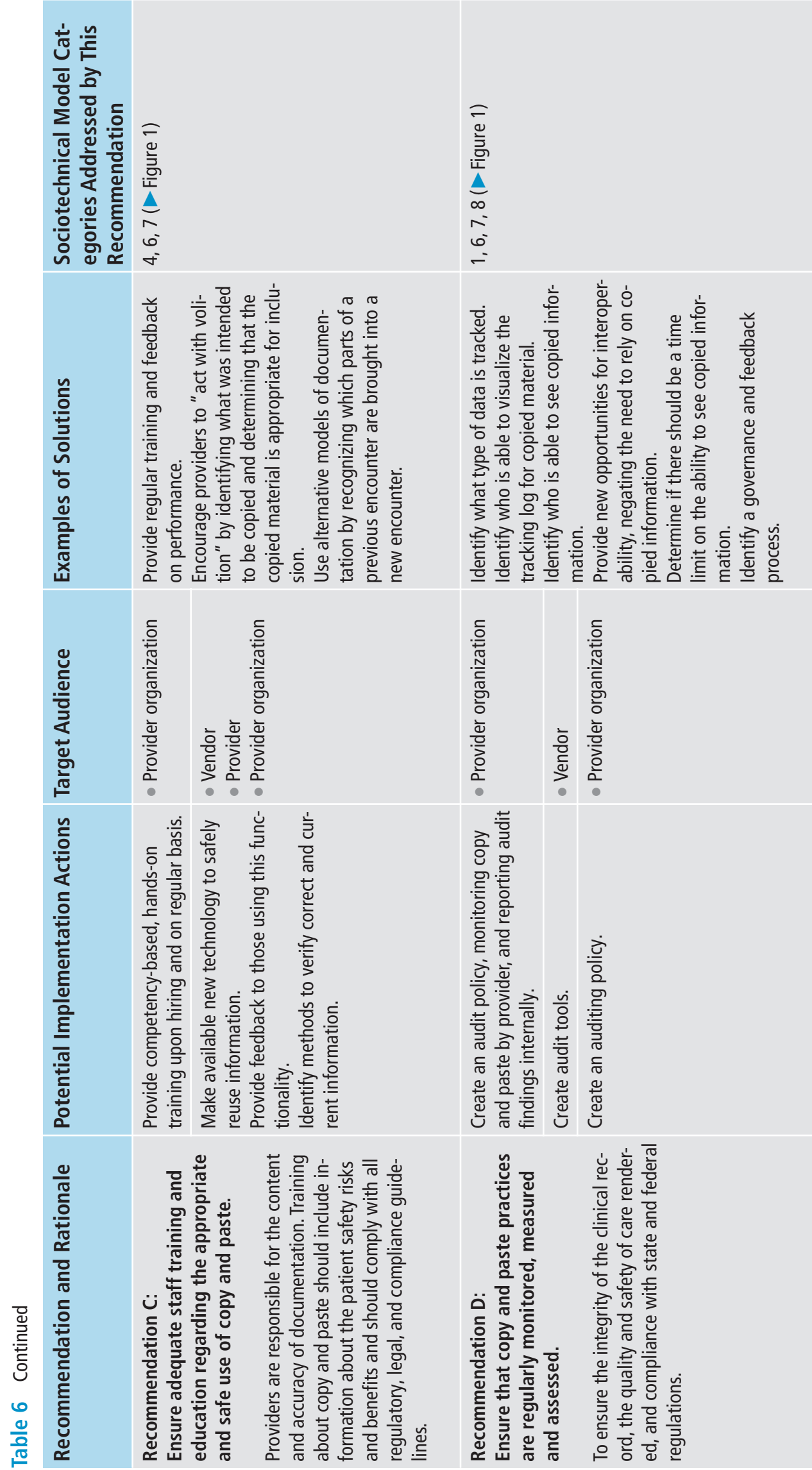


\section{References}

1. O’Donnell HC, Kaushal R, Barron Y, Callahan MA, Adelman RD, Siegler EL. Physicians' attitudes towards copy and pasting in electronic note writing. J Gen Intern Med 2009; 24(1): 63-68. Available from: http://dx.doi.org/10.1007/s11606-008-0843-2. PubMed PMID: 18998191.

2. Appropriate use of the copy and paste functionality in electronic health records. Chicago (IL): American Health Information Management Association; 2014; 7p. Available from: http://library.ahima.org/xpedio/ groups/public/documents/ahima/bok1_050621.pdf.

3. Shoolin JS, Ozeran L, Hamann C, Bria II W. Association of medical directors of information systems consensus on inpatient electronic health record documentation. Appl Clin Inform 2013; 4(2): 293-303. Available from: http://dx.doi.org/10.4338/ACI-2013-02-R-0012. PubMed PMID: 23874365.

4. Office of Inspector General. Not all recommended fraud safeguards have been implemented in hospital EHR technology. Washington (DC): U.S. Department of Health and Human Services; 2013 Dec. 27 p. Available from: https://oig.hhs.gov/oei/reports/oei-01-11-00570.pdf.

5. Sittig DF, Singh H. A new sociotechnical model for studying health information technology in complex adaptive healthcare systems. Qual Saf Health Care 2010; 19(Suppl. 3): i68-i74. Available from: http://dx.doi.org/10.1136/qshc.2010.042085. PubMed PMID: 20959322.

6. Swary J, Stratman EJ. Practice gaps in patient safety among dermatology residents and their teachers: a survey study of dermatology residents. JAMA Dermatology 2014; 150(7): 738-742.

7. Edwards ST, Neri PM, Volk LA, et al. Association of note quality and quality of care: a cross-sectional study. BMJ Qual Saf 2014; 23(5): 406-413. Available from: http://dx.doi.org/10.1136/bmjqs-2013-002194.

8. Thornton JD, Schold JD, Venkateshaiah L, Lander B. Prevalence of copied information by attendings and residents in critical care progress notes. Crit Care Med 2013; 41(2): 382-388. Available from: http://dx.doi.org/10.1097/CCM.0b013e3182711a1c. PubMed PMID: 23263617.

9. Thielke S, Hammond K, Helbig S. Copying and pasting of examinations within the electronic medical record. Int J Med Inform 2007; 76 (Suppl. 1): S122-S128. Available from: http://dx.doi.org/10.1016/j.ijmedinf.2006.06.004. PubMed PMID: 16899403.

10. Weir CR, Hurdle JF, Felgar MA, Hoffman JM, Roth B, Nebeker JR. Direct text entry in electronic progress notes. An evaluation of input errors. Methods Inf Med 2003; 42(1): 61-67. Available from: http://dx.doi.org/10.1267/METH03010061. PubMed PMID: 12695797.

11. Singh H, Giardina TD, Meyer AN, Forjuoh SN, Reis MD, Thomas EJ. Types and origins of diagnostic errors in primary care settings. JAMA Intern Med 2013; 173(6): 418-425. Available from: doi: 10.1001/jamainternmed.2013.2777. PubMed PMID: 23440149.

12. Turchin A, Goldberg SI, Breydo E, Shubina M, Einbinder JS. Copy/paste documentation of lifestyle counseling and glycemic control in patients with diabetes: True to form? Arch Intern Med 2011; 171(15): 1393-1394. Available from: http://dx.doi.org/10.1001/archinternmed.2011.219. PubMed PMID: 21606091.

13. Hirschtick R. Case \& commentary: sloppy and paste. Rockville (MD): AHRQ WebM\&M; 2012 Jul [cited 2015 Mar 20]. [4 p]. Available from: http://webmm.ahrq.gov/printviewCase.aspx?caseID=274.

14. O’Reilly KB. EHRs: "sloppy and paste" endures despite patient safety risk. [internet]. Chicago (IL): American Medical Association; 2013 Feb 4 [cited 2015 Mar 23]. [4 p]. Available from: http://www.amednews. com/article/20130204/profession/130209993/2/.

15. Hersh W. Cases \& commentaries: copy and paste. Rockville (MD): AHRQ WebM\&M; 2007 Jul-Aug [cited 2015 Mar 23]. [3 p]. Available from: http://webmm.ahrq.gov/printviewCase.aspx?caseID=157.

16. Samaritan GA. Standard of care deviation results in patient's death. Copy \& paste documentation not helpful to the defense. J Med Assoc Ga 2010; 99(2): 32-33. PubMed PMID: 20718159.

17. Troxel DB. Analysis of EHR contributing factors in medical professional liability claims. Doctors Advocate 2015; 2, 6-7, 9. Available from: http://www.thedoctors.com/KnowledgeCenter/Publications/TheDoctors Advocate/con_id_006908?utm_campaign=The+Doctor\%27s+Advocate\&utm_source=hs_email\&utm_ medium=email\&utm_content=16657687\&_hsenc=p2ANqtz-8DrHdkNKwFEyj8X6Mu1x26V3Fexllq6h6y fDr6vuB1gQymfGYO29qpEKdyF7ed5iGRTjY9j5z7wYeE8JqVL9CCGUnZMw\&_hsmi=16657687.

18. Copy and Paste in ED: "Dangerous Practice". ED Legal Letter 2012; 23(11): 129-132.

19. Markel A. Copy and paste of electronic health records: a modern medical illness. Am J Med 2010; 123(5): e9. Available from: http://dx.doi.org/10.1016/j.amjmed.2009.10.012. PubMed PMID: 20399309.

20. Wrenn JO, Stein DM, Bakken S, Stetson PD. Quantifying clinical narrative redundancy in an electronic health record. J Am Med Inform Assoc 2010; 17(1): 49-53. Available from: http:/dx.doi.org/ 10.1197/jamia.M3390. PubMed PMID: 20064801.

21. Haugen H. Overcoming the risks of copy and paste in EHRs. J AHIMA 2014; 85(6): 54-55. PubMed PMID: 25022056.

22. Zittel J. Mistake Noted. Acad Med 2012; 87(8): 1090. 
23. Weis JM, Levy PC. Copy, paste, and cloned notes in electronic health records; prevalence, benefits, risks, and best practice recommendations. Chest 2014; 145(3): 632-638. Available from: http://dx.doi.org/10.1378/chest.13-0886. PubMed PMID: 24590024.

24. Tamburello LM. The road to EMR noncompliance and fraud is paved with cut and paste. MD Advis 2013; 6(4): 24-30. PubMed PMID: 24165537.

25. Bowman S. Impact of electronic health record systems on information integrity: quality and safety implications. Perspect Health Inf Manag 2013; 10: 1c. PubMed PMID: 24159271.

26. Berkowitz L. Change doctor: in defense of copy-forward! Chicago (IL): drlyle.blogspot.com; 2013 Jan 29 [cited 2015 Mar 20]. [4 p]. Available from: http://drlyle.blogspot.com/2013/01/in-defense-of-copy-forward_29.html.

27. ACDIS releases EHR position paper. cdi J 2013; 7(4): 1-8. Available from: http://www.hcpro.com/con tent/297249.pdf.

28. Arrowood D, Choate E, Curtis E, DeCathelineau S, Drury B, Fenton S, et al. Integrity of the healthcare record. Best practices for EHR documentation. J AHIMA 2013; 84(8): 58-62. PubMed PMID: 23984510.

29. Kuhn T, Basch P, Barr M, Yackel T, for the Medical Informatics Committee of the American College of Physicians. Clinical documentation in the 21st century: executive summary of a policy position paper from the American College of Physicians. Ann Intern Med 2015; 162(4): 301-303. Available from: http://dx.doi.org/10.7326/M14-2128. PubMed PMID: 25581028.

30. Report of the Committee on Ethics and Professionalism in the adoption and use of Electronic Health Records. Euless (TX): Federation of State Medical Boards; 2014 Apr. 27 p. Available from: http://www.fsmb. org/Media/Default/PDF/FSMB/Advocacy/ehr_framework_final_adopted.pdf.

31. Zhang M, Shubina M, Morrison F, Turchin A. Following the money: copy-paste of lifestyle counseling documentation and provider billing. BMC Health Serv Res 2013; 13: 377. Available from: http://dx.doi.org/10.1186/1472-6963-13-377. PubMed PMID: 24225135.

32. Senathirajah Y, Kaufman D, Bakken S. Beyond copy and paste: clinician approaches to meeting information needs during note writing. Stud Health Technol Inform 2014; 205: 599-603. PubMed PMID: 25160256.

33. Koppel R. Illusions and delusions of cut, pasted, and cloned notes: ephemeral reality and pixel prevarications. Chest 2014; 145(3): 444-445. Available from: http://dx.doi.org/10.1378/chest.13-1846. PubMed PMID: 24590015.

34. No need to disable ctrl-c/ctrl-v in EHRs. Healthc Risk Manag 2014; 36(3): 43-44.

35. Hirschtick RE. John Lennon's elbow. JAMA 2012; 308(5): 463-464.

36. Reinke CE, Kelz RR, Baillie CA, Norris A, Schmidt S, Wingate N, et al. Timeliness and quality of surgical discharge summaries after the implementation of an electronic format. Am J Surg 2014; 207(1): 7-16. Available from: http://dx.doi.org/10.1016/j.amjsurg.2013.04.003. PubMed PMID: 24269034.

37. Magrabi F, Ong MS, Runciman W, Coiera E. Using FDA reports to inform a classification for health information technology safety problems. J Am Med Inform Assoc 2012; 19(1): 45-53. PubMed PMID: 21903979.

38. Supporting documents - Common Formats - Hospital Version 1.2. Rockville (MD): Patient Safety Organization Privacy Protection Center, Agency for Healthcare Research and Quality; [cited 2016 Aug 12]. [5 p]. Available from: https://www.psoppc.org/psoppc_web/publicpages/supportingDocsV1.2\#.

39. Walker JM, Hassol A, Bradshaw B, Rezaee ME. Health IT hazard manager beta-test: Final report. (Prepared by Abt Associates and Geisinger Health System under Contract No. HHSA290200600011i, \#14). AHRQ Publication No. 12-0058-EF. Rockville (MD): Agency for Healthcare Research and Quality; 2012. 69 p. Available from: https://healthit.ahrq.gov/sites/default/files/docs/citation/HealthITHazardManagerFinalReport.pdf.

40. Institute of Medicine. Graham R, Mancher M, Wolman DM, Greenfield S, Steinberg E, editors. Clinical practice guidelines we can trust. Washington (DC): National Academies Press; 2011. 291 p. Available from: http://www.iom.edu/Reports/2011/Clinical-Practice-Guidelines-We-Can-Trust/Standards.aspx.

41. Heiman HL, Rasminsky S, Bierman JA, Evans DB, Kinner KG, Stamos J, et al. Medical students' observations, practices, and attitudes regarding electronic health record documentation. Teach Learn Med 2014; 26(1): 49-55. Available from: http://dx.doi.org/10.1080/10401334.2013.857337. PubMed PMID: 24405346.

42. Tilstra SA, Hasley P, Munshi A, Heist BS, Zimmer SM, Hariharan J. The (electronic) chart war: resident and faculty perceptions and practices in outpatient documentation and chart management. J Gen Intern Med. 2014 Apr.

43. Chang R, Stewart D, Ibach B, Laing T. Epidemiology of copy and pasting in the medical record at a tertiary-care academic medical center. J Hosp Med 2012; 7(Suppl. 2): 130. Available from:

http://dx.doi.org/10.1002/jhm.1927. 
44. Hammond KW, Helbig ST, Benson CC, Brathwaite-Sketoe BM. Are electronic medical records trustworthy? Observations on copying, pasting and duplication. AMIA Annu Symp Proc 2003; 269-273. PubMed PMID: 14728176.

45. Shah CC, Linam L, Greenberg SB. Inappropriate and cloned clinical histories on radiology request forms for sick children. Pediatr Radiol 2013; 43(10): 1267-1272. Available from: http://dx.doi.org/10.1007/s00247-013-2648-7. PubMed PMID: 23649204.

46. Mamykina L, Vawdrey DK, Stetson PD, Zheng K, Hripcsak G. Clinical documentation: composition or synthesis? J Am Med Inform Assoc 2012; 19(6): 1025-1031. Available from: http://dx.doi.org/ 10.1136/amiajnl-2012-000901. PubMed PMID: 22813762.

47. 'Copy-and-paste' fraud targeted by CMS and OIG. Healthc Risk Manag 2014; 36(3): 41-43.

48. Canham EM, Weaver MJ. Copy, paste, and cloned electronic records. Chest 2014; 146(3): e101. Available from: http://dx.doi.org/10.1378/chest.14-0759.

49. Payne TH, tenBroek AE, Fletcher GS, Labuguen MC. Transition from paper to electronic inpatient physician notes. J Am Med Inform Assoc 2010; 17(1): 108-111. Available from: http://dx.doi.org/ 10.1197/jamia.M3173. PubMed PMID: 20064811. 